\title{
The grammar behind word association tasks
}

\author{
Sydelle de Souza ${ }^{1,2}$, Alina Villalva ${ }^{1,2}$, Carina Pinto ${ }^{2,3,4}$ \\ ${ }^{1}$ Faculdade de Letras, Universidade de Lisboa, Portugal \\ ${ }^{2}$ Centro de Linguística, Universidade de Lisboa, Portugal \\ ${ }^{3}$ Escola Superior de Saúde, Politécnico da Leiria, Portugal \\ ${ }^{4}$ Centro de Inovação em Tecnologias e Cuidados de Saúde, Portugal \\ https://doi.org/10.36505/ExLing-2020/11/0021/000436
}

\begin{abstract}
Most word association tasks (WATs) focus on semantic representations but can also illuminate other linguistic phenomena (Van Rensbergen et al., 2015). This study reports a WAT comprising 152 Portuguese verbs and their corresponding compositional deverbal action nouns ending in -ção, that aims to test whether the morphological nature of the stimulus conditions the response. The results suggest that (i) the morphological structure of the stimuli does condition the response; (ii) associations can be constrained by grammatical factors other than semantics; and (iii) L1 Portuguese speakers are more likely to respond with a word belonging to the same word family if the stimulus is a complex word.
\end{abstract}

Keywords: morphological processing, Portuguese, word association task, lexical semantics, complex words

\section{Introduction and theoretical background}

The first known word association task (WAT) was performed by Sir Francis Galton in 1883 (Galton, 1907) and has since been frequently used by experimental and differential psychologists. Later, WATs became instrumental in experimental linguistics and research pertaining to the mental lexicon (Clark, 1970). They have been used to study semantic and lexical access in a variety of areas ranging from child language acquisition (Sheng et al., 2014) and second language acquisition (Nissen \& Henriksen, 2006; Zhang \& Koda, 2017) to clinical studies involving dementia (Eustache et al., 1990) and deep dyslexia (Colangelo et al., 2003). Although most WATs only focus on semantic representations, it has been argued that data obtained from them "often shed light on other linguistic phenomena as well" (Van Rensbergen et al., 2015).

The instructions - read the following words and write the first word that comes to your mind - raise doubts about whether the response is truly the first word that comes to the subject's mind. These doubts along with the emergence of other sophisticated methodologies led to the decline of WATs. However, a recent study by Playfoot et al. (2018) claiming that "word association responses are likely to reflect the first word that participants activate in their lexicon", may justify a revival.

ExLing 2020: Proceedings of $11^{\text {th }}$ International Conference of Experimental Linguistics, 12-14 October 2020, Athens, Greece 
Therefore, the present study aims to determine (a) if WATs are constrained by grammatical factors other than semantics, (b) if the morphological structure of the stimuli triggers specific types of responses, and (c) if L1 Portuguese speakers favor certain lexical activation pathways for complex words.

\section{Methodology}

A WAT comprising 152 Portuguese verbs (e.g. aceitar 'to accept') and their corresponding deverbal action nouns, formed by the suffix -ção (e.g. aceitação 'acceptance') was constructed. Frequency values were considered (Corpus de Referência do Português Contemporâneo) and the stimuli (2-6 syllables) were divided into: high (>1000 tokens), medium (101-1000 tokens), and low frequency $(<100$ tokens) words.

The subject sample consisted of 22 proficient native speakers of European Portuguese (EP). All were university students $\left(\mathrm{M}_{\text {Age }} 20\right.$ years \pm 1.95$)$ and presented no language pathologies. The task, executed individually through Google Forms, was completed in approximately 90 minutes. All participants were present in the same room and were instructed to enter the first word that occurred to them on reading the stimuli.

6688 responses were collected and manually tagged based on their relationship to the stimulus, according to the following categorization:

A. Strictly semantic relationship: Synonyms, hyponyms, etc. (acusar 'to accuse' - culpar 'to blame')

B. Morphosemantic relationship: Derivative of stimulus (ligar 'to connect' - ligação 'connection'), stimulus base word (aceitação 'acceptance'-aceitar 'to accept'), parallel derivatives of the base word (admiração 'admiration' - admirável 'admirable')

C. Syntagmatic relationship: Complement or modifier of the stimulus (ligar 'to connect' - telemóvel 'cell phone')

D. Other: Possible phonetic resemblance, grammatically random (e.g. polinizar 'to pollinate' - polir 'to polish')

E. Invalid: Response is not a word

F. No response

\section{Results and discussion}

The results show that only $6.3 \%$ of the total responses are random, invalid, or no responses while all other responses are grammatically linked to the stimulus. Global results $(\mathrm{N}+\mathrm{V})$ show that $46.3 \%$ of the responses establish a strictly semantic relationship and $33.9 \%$ a morphosemantic relationship. Syntagmatic relationships were established in $13.5 \%$ of the responses. Disaggregating the global results by word-class ( $\mathrm{N}$ vs. $\mathrm{V}$ ) shows a noticeable 
stability for the syntagmatic relationship $(\mathrm{N}=13.6 \%, \mathrm{~V}=13.4 \%)$ and a deviation close to $5 \%$ in the other two cases (Table 1 ).

Table 1. Global Results N vs. V.

\begin{tabular}{|l|l|l|l|l|}
\hline & $\begin{array}{l}\text { Semantic } \\
\text { Relationship (A) }\end{array}$ & $\begin{array}{l}\text { Morphosemantic } \\
\text { Relationship (B) }\end{array}$ & $\begin{array}{l}\text { Syntagmatic } \\
\text { Relationship (C) }\end{array}$ & $\begin{array}{l}\text { Other } \\
(\mathrm{D}+\mathrm{E}+\mathrm{F})\end{array}$ \\
\hline Nouns & $43.8 \%$ & $36.2 \%$ & $13.6 \%$ & $6.4 \%$ \\
\hline Verbs & $48.8 \%$ & $31.5 \%$ & $13.4 \%$ & $6.3 \%$ \\
\hline
\end{tabular}

The semantic pathway percentage is higher for verbs, and the morphological pathway is higher for nouns, confirming the hypothesis that the morphological nature of the stimulus triggers certain types of responses. A further disaggregation of the results by morphological complexity (simplex $\mathrm{V}$ vs. complex $\mathrm{V}$ and $\mathrm{N}$ ) shows that complex words elicit increased morphologically related responses, i.e., morphological activation is clearly triggered by morphologically complex stimuli (Fig. 2).

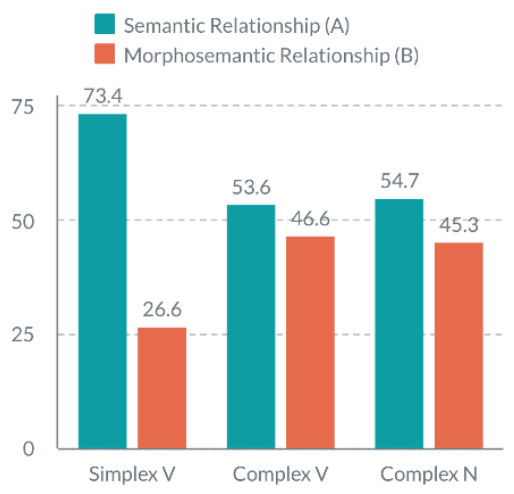

Figure 2. Simplex V vs. complex $\mathrm{V}$ and $\mathrm{N}$.

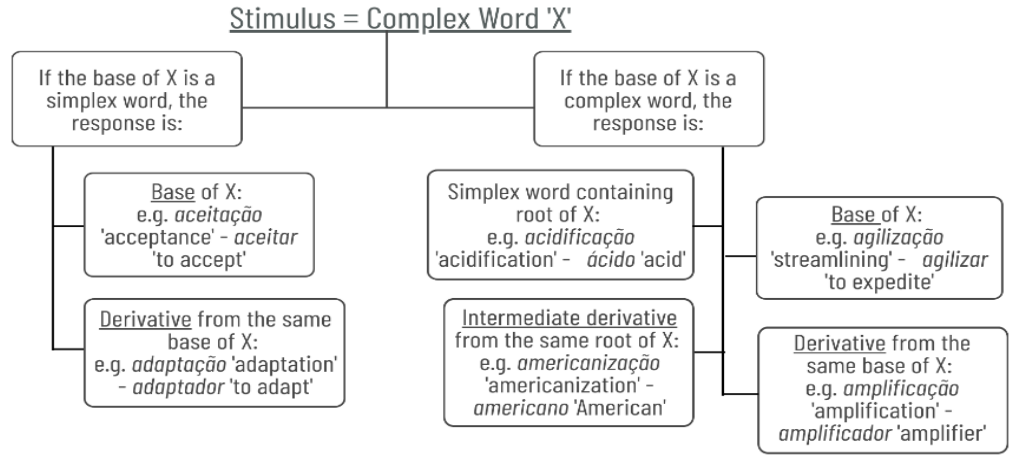

Figure 3. Typology of responses. 
Additionally, simplex words containing the embedded root appear to be the most popular choice when a morphological response is given. Therefore, irrespective of the degree of complexity of the derivative, the embedded lexeme seems to be successfully identified (Fig. 3).

\section{Conclusion}

In sum, the results suggest that the morphological structure of the stimuli is of paramount importance to the response and that word associations are constrained by grammatical factors other than semantics. Finally, for complex stimuli, L1 Portuguese speakers are more likely to respond with a word belonging to the same word family. As this sample is limited to deverbal action nouns ending in -ção, the findings cannot be extrapolated to other complex words without replicating this test. Other tests have been performed with complex words ending in -vel and -dor. Their results are currently under analysis.

\section{References}

Clark, H. H. 1970. Word Associations and Linguistic Theory. New Horizons in Linguistics, 1-8.

Colangelo, A., Stephenson, K., Westbury, C., Buchanan, L. 2003. Word associations in deep dyslexia. Brain and Cognition, 53(2), 166-170.

Eustache, F., Cox, C., Brandt, J., Bernard, L., Pons, L. 1990. Word-Association Responses and Severity of Dementia in Alzheimer Disease. Psychological Reports, 66(4), 1315-1322.

Galton, F. 1907. Inquiries into Human Faculty and its Development (Everyman S). J. M. Dent \& Co. https://doi.org/10.16309/j.cnki.issn.1007-1776.2003.03.004

Nissen, H. B., Henriksen, B. 2006. Word class influence on word association test results. International Journal of Applied Linguistics, 16(3), 389-408.

Playfoot, D., Balint, T., Pandya, V., Parkes, A., Peters, M., Richards, S. 2018. Are word association responses really the first words that come to mind? Applied Linguistics, 39(5), 607-624.

Sheng, L., Mcgregor, K. K., Marian, V. 2014. Lexical - Semantic Organization in Bilingual Children : Evidence From a Repeated Word Association Task. Journal of Speech Language and Hearing Research, 49(June 2006), 572-587.

Van Rensbergen, B., Storms, G., De Deyne, S. 2015. Examining assortativity in the mental lexicon: Evidence from word associations. Psychonomic Bulletin and Review, 22(6), 1717-1724.

Zhang, D., Koda, K. 2017. Assessing L2 vocabulary depth with word associates format tests: issues, findings, and suggestions. Asian-Pacific Journal of Second and Foreign Language Education, 2(1), 1-30. 